ECCOMAS

Proceedia
COMPDYN 2021

$8^{\text {th }}$ ECCOMAS Thematic Conference on Computational Methods in Structural Dynamics and Earthquake Engineering

M. Papadrakakis, M. Fragiadakis (eds.)

\title{
THE EFFECT OF IMPACT MODELING ON THE SEISMIC RESPONSE OF MULTI-STOREY PODIUM STRUCTURES
}

\author{
Ioannis E. Kavvadias ${ }^{1}$, Kosmas E. Bantilas ${ }^{1}$, Lazaros Vasiliadis $^{1}$, Anaxagoras Elenas ${ }^{1}$ \\ ${ }^{1}$ Department of Civil Engineering, Democritus University of Thrace \\ Campus of Kimmeria, Xanthi 67100, Greece \\ e-mail: \{ikavvadi, kbantila, lvasilia, elenas\}@civil.duth.gr
}

\begin{abstract}
In the present study the effect of impact modeling on the seismic response of multi-storey structures placed on the top of a rocking storey is examined. For this purpose, two impact models are introduced, where the energy dissipation is treated using the angular momentumimpulse theorem combined with different assumptions regarding the post-impact state of the superstructure. The effect of the examined impact models on the dynamic response of nine typical multi-storey podium structures is assessed using synthetic pulse-like ground motion records. The superstructures are divided in three classes based on the lateral displacement profile of their fundamental vibration mode. Thus, the effect of the impact model on the maximum rocking rotations and elastic seismic demands as a function of the superstructure's dynamic properties is investigated. The study concludes that the impact model presents a minor effect on the rocking response of the podium structure. On the contrary, it might substantially affect both the magnitude and the distribution of the seismic demands, especially in cases of stiff superstructures with flexural displacement profile.
\end{abstract}

Keywords: Rocking structures; Podium structures; Impact model; Synthetic ground motions 


\section{INTRODUCTION}

The dynamic response of rigid blocks rocking on a rigid ground was first studied by Housner [1], who highlighted the parameters that affect the stability of rigid bodies which can be uplifted under horizontal excitations. Since then, with the recognition of the remarkable properties of the rocking response, various forms of rocking systems have been studied, such as flexible rocking oscillators on solid [2-6] and flexible ground [7, 8], rocking structures on the foundations [9], rocking bridge piers [10-12], rocking frames[13-17], coupled conventional structures with rocking walls [18-20]. Regarding the seismic isolation by forming a rocking floor at the base [21-24], the first analytical study was carried out by Bachmann et al. [21]. Subsequently, Bantilas et al. [22] investigated the structural and the ground motion parameters that affect the elastic demands of rocking podium structures (RPSs), while Bantilas et al. [23] examined the effect of the higher vibration modes of multi-storey superstructures on the dynamic response of RPSs.

Due to the strongly non-linear behavior of the rocking motion, small changes in both the rocking system and the ground motion parameters can lead to large variations in the response, so that the study of the phenomenon under a probabilistic framework yields more reliable conclusions [24]. To this end, except of the investigation of the influence of ground excitation characteristics on the dynamic response of rocking systems [25-30], the effect of modeling assumptions on the rocking response is of great interest.

In the rocking response of rigid blocks, energy dissipation occurs during impact when the tilt angle of the rocking columns reverses the sign. Although different models for energy dissipation have been proposed [31-33], Housner's coefficient of restitution [1] has been widely used. Regarding the energy dissipation during impact, various conservation rules have been proposed in order to evaluate the post impact state of a rocking system. In the case of deformable rocking cantilevers, such approaches involve the conservation of the horizontal momentum [34], conservation of the moment of momentum [35] and conservation of kinetic energy at the horizontal direction [6] combined with the assumption that the vertical velocity of the model is completely dissipated. The above conservation rules led to an increase in the elastic demands especially when applied to stiff systems $[6,36]$. Due to this fact the conservation of horizontal momentum combined with the assumption that the relative velocity between the deformable oscillator and the base is constant during impact were introduced by Oliveto et al. [36]. Since then, the assumption of constant relative velocity has been adopted by other researchers to study the response of both deformable rocking cantilevers [2-3]. Later studies of Giouvanidis and Dimitrakopoulos [37] prove that the relative velocity of a deformable rocking cantilever before and after the impact does not remain constant.

Regarding the podium structures, assuming instantaneous impact and all the impact forces concentrated at the pivot points, the system can be considered isolated and conservation of angular momentum can be applied. Bachmann et al. [21] and Bantilas et al. [23] examined the response of sdof and mdof RPSs respectively, assuming that the relative horizontal velocity of the superstructure with respect to the cap beam of the rocking frame before and after the impact remains constant. Moreover, Bantilas et al. [22] assumed constant absolute horizontal velocity of the superstructure during impact, in order to investigate the effect of the impact modeling assumption on the response of sdof RPSs. In the present study the effect of the two aforementioned impact assumptions on the response of multi-storey RPSs is investigated. Thus, nine multi-storey RPSs are examined under a set of synthetic pulse-like ground motion records, in order to assess the effect of the energy dissipation model on the response of the rocking base, as well as the elastic seismic demands. 


\section{DYNAMIC RESPONSE OF ROCKING PODIUM STRUCTURES}

In the present section, the analytical model of the dynamic response of frame structures, seismically isolated using a rocking story, is presented. The model is based on the assumption that the superstructure is described by a mdof elastic oscillator, fixed on the top of a rigid rocking frame. The rigid frame consists of a cap beam with mass $\mathrm{m}_{\mathrm{b}}$ and $\mathrm{N}$ freestanding columns with mass $m_{c}$, semi-diagonal length $\mathrm{R}=\sqrt{\mathrm{H}^{2}+\mathrm{B}^{2}}$, rotational moment of inertia around its center of mass $\mathrm{I}_{\mathrm{cm}}$, and slenderness $\alpha=\operatorname{atan}(\mathrm{B} / \mathrm{H})$. During the dynamic response, the rocking columns are considered to be in contact with the cap beam and the ground, while the friction coefficient at the contact surfaces is large enough to prevent any sliding. The schematic representation of the model is illustrated in Figure 1.

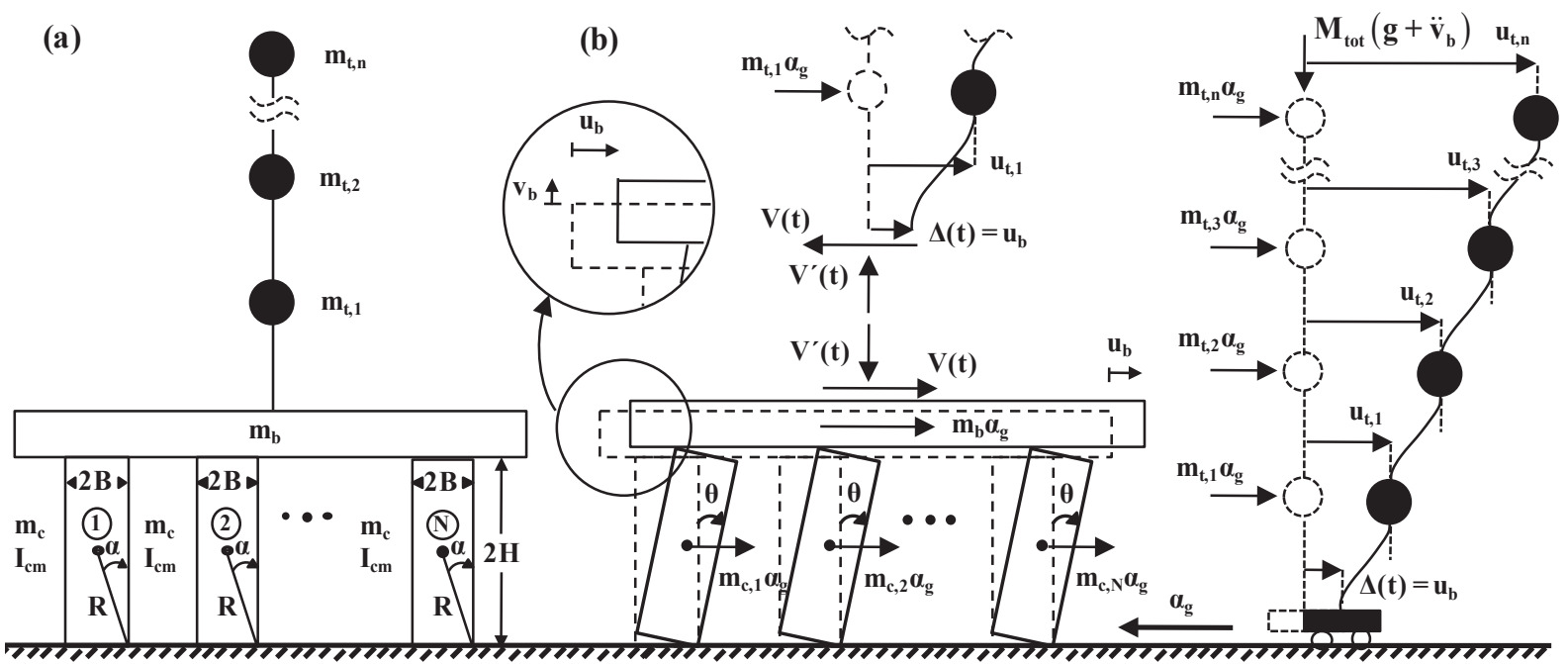

Figure 1: Schematic representation of the analytical model of multi-storey rocking isolated structures (a) and interaction of the rocking base with the superstructure (b).

The analytical presentation of the assumptions related to the model used herein is provided by Bantilas et al. [23]. The equations of motion of the sub-system of the rocking base, as well as the superstructure are given by Equation (1) and (2), respectively.

$$
\begin{gathered}
{\left[\overline{\mathrm{I}}_{\mathrm{o}}+4 \gamma+4 \eta \gamma \sin ^{2}(\alpha \mp \theta)\right] \mathrm{R} \ddot{\theta}= \pm 2 \eta \gamma \mathrm{R} \sin [2(\alpha \mp \theta)] \dot{\theta}^{2} \mp} \\
\mp(1+2 \eta \gamma+2 \gamma) g \sin (\alpha \mp \theta)-(1+2 \gamma) \alpha_{\mathrm{g}} \cos (\alpha \mp \theta)+\frac{\mathrm{V}}{\mathrm{M}_{\mathrm{tot}}} 2 \eta \gamma \cos (\alpha \mp \theta) \\
\mathbf{M} \ddot{\mathbf{u}}_{\mathrm{t}}+\mathbf{C} \dot{\mathbf{u}}_{\mathrm{t}}+\mathbf{K} \mathbf{u}_{\mathrm{t}}=-\mathbf{M} \boldsymbol{\delta} \alpha_{\mathrm{g}}+\mathbf{K} \boldsymbol{\delta} \underbrace{[ \pm 2 \mathrm{R}(\sin (\alpha)-\sin (\alpha \mp \theta))]}_{\mathrm{u}_{\mathrm{b}}}+\mathbf{C} \boldsymbol{\delta} \underbrace{2 \mathrm{R} \cos (\alpha \mp \theta) \dot{\theta}}_{\mathrm{u}_{\mathrm{b}}}
\end{gathered}
$$

where $\gamma$ is the mass ratio of the cap beam $\left(\mathrm{m}_{\mathrm{b}}\right)$ divided by the total mass of rocking columns $\left(\mathrm{Nm}_{\mathrm{c}}\right) ; \eta$ is the mass ratio of the superstructure (Mtot) divided by the mass of cap beam $(\mathrm{mb})$; $\overline{\mathrm{I}}_{\mathrm{o}}=\mathrm{I}_{\mathrm{o}} /\left(\mathrm{m}_{\mathrm{c}} \mathrm{R}^{2}\right)$ and $\mathrm{I}_{\mathrm{o}}$ is the rotational inertia of the column with respect to the pivot point; $\theta$, $\dot{\theta}$ and $\ddot{\theta}$ are the title angle, the rotational velocity and the rotational acceleration of the rocking columns; $\vec{u}_{t}, \dot{u}_{t}$ and $\ddot{u}_{t}$ are the floor displacements, velocities and accelerations with respect to the undeformed configuration of the system; $\mathbf{M}, \mathbf{K}$ and $\mathbf{C}$ are the mass the stiffness and the damping matrix of the superstructure; $\boldsymbol{\delta}$ is the influence vector of the ground motion $(\boldsymbol{\delta}=\mathbf{1}) ; \alpha_{\mathrm{g}}$ is the ground acceleration; $\mathrm{ub}_{\mathrm{b}}$ and $\mathrm{vb}$ the horizontal and vertical displacements of the center of mass of the cap beam; and the base shear of the superstructure (V) is given by: 


$$
\mathrm{V}=\boldsymbol{\delta}^{\mathrm{T}} \mathbf{K}\left(\mathbf{u}_{\mathrm{t}} \mp \boldsymbol{\delta} \mathrm{u}_{\mathrm{b}}\right)+\boldsymbol{\delta}^{\mathrm{T}} \mathbf{C}\left(\dot{\mathbf{u}}_{\mathrm{t}}-\boldsymbol{\delta} \dot{\mathrm{u}}_{\mathrm{b}}\right)
$$

The terms $\mathbf{K} \boldsymbol{\delta} \mathrm{u}_{\mathrm{b}}$ and $\mathbf{C} \boldsymbol{\delta} \dot{\mathrm{u}}_{\mathrm{b}}$ correspond to the dynamic loads applied to the superstructure due to the continuous displacement of the cap beam of the rocking base. The upper and lower signs in Eqs. (1)-(3) define rocking around the right $(\theta>0)$ and left $(\theta<0)$ pivot points of the rocking columns respectively.

Until uplift occurs, the rocking base is assumed to remain inactive $(\theta=\dot{\theta}=0)$. Thus the superstructure behaves as a fixed base mdof oscillator, and the equations of motion are given by Eq. (2), considering $\mathrm{u}_{\mathrm{b}}=\dot{\mathrm{u}}_{\mathrm{b}}=0$. When the horizontal overturning actions overcome the restoring forces of the podium structure, uplift occurs, and the rocking story starts to roll. The uplift criteria can be summarized as follows:

$$
\mp \frac{\alpha_{\mathrm{g}}}{\mathrm{g}} \geq\left(1+\frac{2 \eta \gamma}{1+2 \gamma}\right) \tan \alpha \mp \frac{2 \eta \gamma}{(1+2 \gamma) \mathrm{M}_{\text {tot }} \mathrm{g}} \mathrm{V}
$$

where $V$ is the superstructure's base shear given by Eq. (3) considering $u_{b}=\dot{u}_{b}=0$. The upper and lower signs define rolling initiation around the right $(\theta>0)$ and left $(\theta<0)$ pivot points.

\section{IMPACT MODELING}

In the present study, in order to evaluate the influence of the adopted energy dissipation model on the elastic response of multi-storey RPSs, two different assumptions regarding the velocity of the superstructure during impact are examined.

Due to the constant relative horizontal velocity (CRV) of the superstructure with respect to the cap beam of the rocking frame before and after the impact assumption, the coefficient of restitution $(\mathrm{COR} \mathrm{CRV})$ and post-impact horizontal velocities of the floors of the superstructure are given by Eqs. (5.a) and (5.b), respectively.

$$
\begin{gathered}
\mathrm{COR}_{\mathrm{CRV}}=\frac{\dot{\theta}^{+}}{\dot{\theta}^{-}}=1-2 \sin ^{2} \alpha \frac{1+4 \gamma(1+\eta)}{\overline{\mathrm{I}}_{\mathrm{o}}+4 \gamma(1+\eta)} \\
\dot{\mathbf{u}}_{\mathrm{t}}^{+}=\dot{\mathbf{u}}_{\mathrm{t}}^{-}-2 \mathrm{R} \cos (\alpha) \dot{\theta}^{-}\left(1-\mathrm{COR}_{\mathrm{CRV}}\right)
\end{gathered}
$$

Additionally, the solution of the impact problem adopting the constant absolute velocity (CAV) assumption results in the coefficient of restitution of the rocking base (COR $\left.\mathrm{CAV}_{\mathrm{V}}\right)$ as well as in the post impact velocities of the superstructure as follows:

$$
\begin{gathered}
\operatorname{COR}_{\mathrm{CAV}}=\frac{\dot{\theta}^{+}}{\dot{\theta}^{-}}=1-2 \sin ^{2}(\alpha) \frac{1+4 \gamma+4 \gamma \eta}{\overline{\mathrm{I}_{\mathrm{o}}}+4 \gamma+4 \gamma \eta \sin ^{2}(\alpha)} \\
\dot{\mathbf{u}}_{\mathrm{t}}^{+}=\dot{\mathbf{u}}_{\mathrm{t}}^{-}
\end{gathered}
$$

where $\dot{\mathbf{u}}_{\mathbf{t}}^{-}$and $\dot{\mathbf{u}}_{\mathbf{t}}^{+}$are the superstructure's absolute velocity vectors before (-) and after $(+)$impact, respectively.

In contrast to the CRV assumption (Eq. 5.b), the CAV assumption (Eq. 6.b) implies that no horizontal impulsive loads are developed on the superstructure which might be crucial for the elastic deformation of the superstructure [36]. In the limit case of an extremely flexible superstructure $\left(\mathrm{T}_{\mathrm{t}} \rightarrow \infty\right)$ the CAV assumption seems well-founded. On the contrary, in the case of a quasi-rigid superstructure $\left(T_{t} \rightarrow 0\right)$ the relative velocity between the superstructure and the cap beam cannot change and as a consequence the CRV assumption is more appropriate. 


\section{SYNTETIC GROUND MOTION RECORDS}

Near-fault ground motions often contain distinct velocity and acceleration pulses, caused primarily by the rapture forward directivity effect [38]. The impulsive characteristics of such ground motions are quite destructive for most civil engineering structures [39] as well as rocking systems [1]. Due to the limited number of recorded pulse-like ground motions, the Mavroeidis and Papageorgiou [40] procedure was adopted to generate synthetic ground motions for a wide range of moment magnitude-distance scenarios $\left(\mathrm{M}_{\mathrm{w}}-\mathrm{R}_{\mathrm{e}}\right)$. According to the model, a pulse-like ground motion can be synthesized by properly superimposing low and high-frequency signals that simulate the coherent directivity pulse and the incoherent seismic radiation, respectively.

The low-frequency component of the synthetic ground motion is modeled using the Mavroeidis and Papageorgiou [40] wavelet. In terms of velocity, the closed-form expression of the analytical pulse is given by:

$$
v(t)=\left\{\begin{array}{c}
\frac{A_{p}}{2}\left[1+\cos \left(\frac{2 \pi}{\gamma_{p} T_{p}}\left(t-t_{0}\right)\right)\right] \cos \left(\frac{2 \pi}{T_{p}}\left(t-t_{0}\right)+v_{p}\right), t_{0}-\gamma_{p} \frac{T_{p}}{2} \leq t \leq t_{0}+\gamma_{p} \frac{T_{p}}{2} \\
0 \quad, \text { otherwise }
\end{array}\right.
$$

where $A_{p}$ controls the amplitude of the signal envelope; $T_{p}$ is the prevailing period of the signal; $v_{p}$ is the phase; $\gamma_{p}$ is a parameter that defines the oscillatory character of the signal $(\gamma>1)$, and $t_{0}$ defines the epoch of the peak of the envelope. For every magnitude-distance $\left(M_{w}-R_{e}\right)$ scenario, a certain low-frequency signal is assumed using the mean values of the Mavroeidis and Papageorgiou pulse parameters $\left(A_{p}, T_{p}, v_{p}, \gamma_{p}\right)$. The mean values of the parameters $v_{p}$ and $\gamma_{p}$ are 1.93 and 1.83, respectively [41]. Moreover, the mean values of the velocity amplitude $\left(\mathrm{V}_{\mathrm{p}}\right)$ and the prevailing period $\left(\mathrm{T}_{\mathrm{p}}\right)$ of the pulse are given by Eqs. (8) and (9) [27]. The envelope parameter $A_{p}$ of Eq. (7) is calculated using the velocity amplitude and the phase of the signal.

$$
\begin{gathered}
\log \left(\mathrm{V}_{\mathrm{p}}\right)=-5.17+1.98 \min \left(\mathrm{M}_{\mathrm{w}}, 7\right)-0.14 \min \left(\mathrm{M}_{\mathrm{w}}, 7\right)^{2}-0.10 \log \left(\mathrm{R}_{\mathrm{e}}^{2}+0.562\right), \mathrm{V}_{\mathrm{p}} \text { in cm } / \mathrm{s} \\
\log \left(\mathrm{T}_{\mathrm{p}}\right)=-2.87+0.47 \mathrm{M}_{\mathrm{w}}, \mathrm{T}_{\mathrm{p}} \text { in s }
\end{gathered}
$$

The high-frequency component of the synthetic ground motion is modeled using the stochastic method. In this approach, the Fourier amplitude spectrum of a windowed white noise is fitted on a "target" amplitude spectrum $Y\left(M_{w}, R_{e}, f\right)$. The "target" spectrum is expressed as a product of quantities which represent the earthquake source radiation $E\left(M_{w}, f\right)$, the propagation path effects $P(R, f)$, the site response $G(f)$, and the type of motion I(f). The fitted amplitude spectrum is transformed back to the time domain, yielding the synthetic high-frequency signal. A detailed review of the method can be found in Boore [42]. In the present study, the model parameters of Atkinson and Silva [43] is adopted to generate high-frequency synthetic time histories for different $\mathrm{M}_{\mathrm{w}}-\mathrm{R}_{\mathrm{e}}$ scenarios.

According to Mavroeidis and Papageorgiou [40], the simulation of a pulse-like synthetic ground motion requires the evaluation of the low and high-frequency components for a given $\mathrm{M}_{\mathrm{w}}-\mathrm{R}_{\mathrm{e}}$ scenario. Subsequently, the Fourier amplitude spectrum of the high-frequency component is subtracted from that of the coherent pulse. Then, the resulting "residual" amplitude spectrum is transformed back to the time domain by considering that its phase coincides with the phase of the Fourier transform of the high-frequency component. Finally, the "residual" high-frequency signal and the low-frequency component are superimposed, yielding the synthetic pulse-like time history. 
In the present study, magnitudes $\mathrm{M}_{\mathrm{w}}$ in the range 5.5-7.5 with a step of 0.5 and distances from the fault $R_{\mathrm{e}}$ in the range $5-20 \mathrm{~km}$ with a step of $2.5 \mathrm{~km}$ were considered $[27,28]$. For every $\mathrm{M}_{\mathrm{w}}-\mathrm{R}_{\mathrm{e}}$ scenario, 100 simulations of pulse-like synthetic ground motions were generated using the aforementioned procedure. For the scope of this study a specific low-frequency signal is assumed for every $\mathrm{M}_{\mathrm{w}}-\mathrm{R}_{\mathrm{e}}$ scenario, using the mean values of the pulse parameters, in order to restrict the ground motion variability and as such to minimize the dependency of the time history analysis results on the characteristics of the signal.

\section{EVALUATION OF IMPACT ASSUMPTIONS}

The effect of the assumptions regarding the velocity of the superstructure during impact on the response of multi-storey RPSs is examined in the present study. The considered multistorey podium structures are divided into three classes, based on the lateral displacements profile of the fundamental vibration mode of the superstructure. For this purpose superstructures with flexural, shear and triangular lateral displacement profile are considered (Figure 2). Considering that in typical multi-storey structures the distribution of floor masses is constant and that the fundamental vibration period of the superstructure is $T_{t, 1}=n / 10$, where $n$ is the number of the floors, the definition of the mass $(\mathbf{M})$ and stiffness $(\mathbf{K})$ matrices are defined, given the lateral displacement profile [23, 44].The damping matrix $(\mathbf{C})$ of each structure is assumed to be proportional to the mass and stiffness matrices (Rayleigh damping) considering critical damping ratio $\xi=5 \%$ for the first two vibration modes. In total nine different superstructures are examined. Specifically, for every displacement profile superstructures with $n=\{3,6,9\}$ floors are considered. All the structures are assumed to be fixed on the top of a typical rocking frame which consists of rectangular columns $\left(\overline{\mathrm{I}}_{\mathrm{o}}=4 / 3\right)$ of size $\mathrm{R}=1.5 \mathrm{~m}$, slenderness $\tan (\alpha)=$ $0.15, \gamma=10$ and cap beam mass $m b$ equal to the mass of the standard floor $m(\eta=n)$.
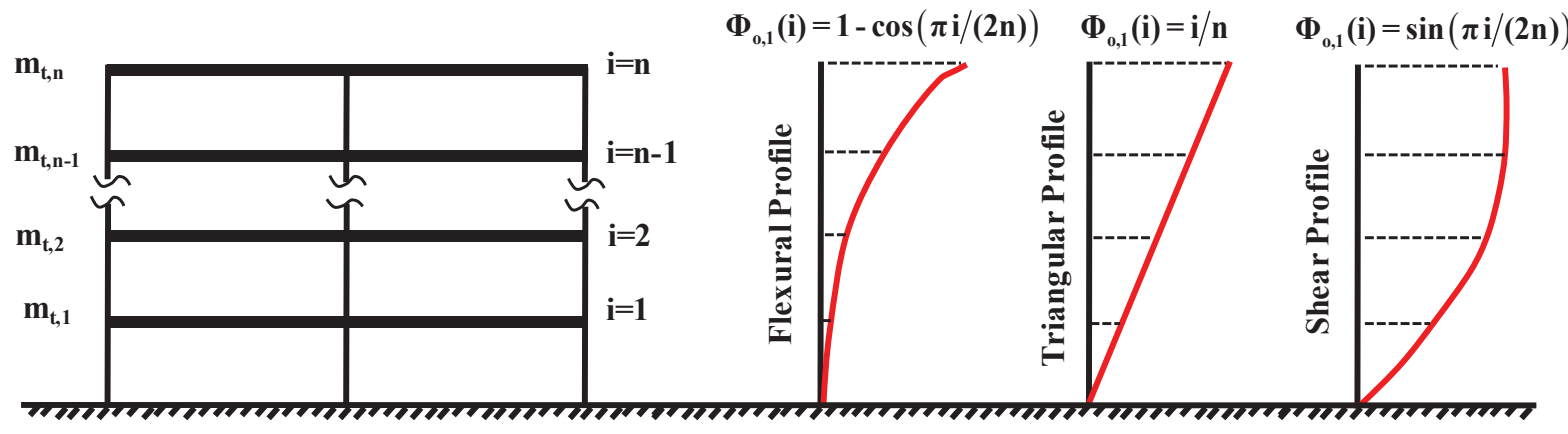

Figure 2: Lateral displacement profiles of the examined multi-storey structures [44].

The values of the coefficient of restitution as obtained by CAV and CRV assumptions are presented in Figure 3. The only feature of the superstructure that affects the coefficient of restitutions is the mass ratio $\eta$. The values of the coefficient of restitution obtained by the CAV assumption are much smaller than the corresponding values under the assumption of CRV. Additionally, the superstructure's mass ratio $(\eta)$ seems to significantly affect the coefficient of restitution under the assumption of CAV. On the other hand the coefficient of restitution under CRV assumption is saturated if the term " $\gamma(1+\eta)$ " of Eq.(5.a) takes values greater than 10 . Thus, for typical RPSs with $\gamma=10$, the coefficient of restitution using CRV assumption is identical for $\eta \geq 1$. 


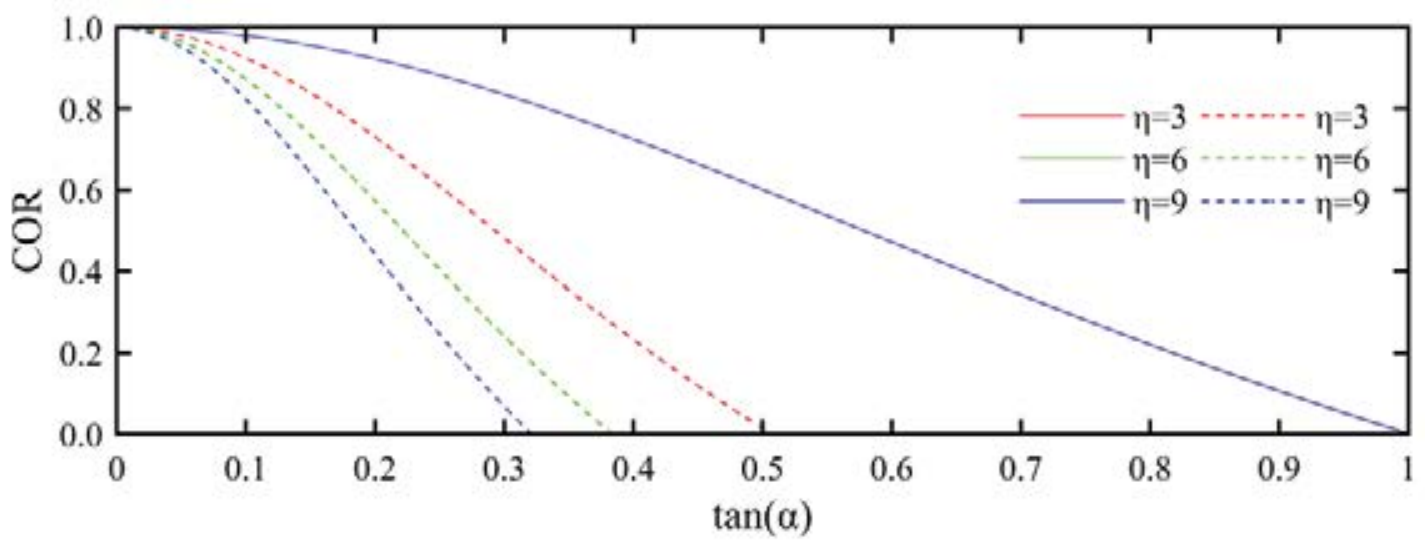

Figure 3: Values of the coefficient of restitution, calculated by the two examined assumptions, as a function of the slenderness $(\alpha)$ of the rocking columns for different values of the superstructure's mass ratio $(\eta)$.

Figure 4 illustrates the responses of three RPSs under free oscillation of the rocking base with initial conditions $\theta_{\mathrm{o}} / \alpha=0.9$ and superstructure's relative deformation $\mathbf{u}_{\mathrm{t}, \mathrm{o}}-\boldsymbol{\delta} \mathbf{u}_{\mathrm{b}, 0}=0$. The $\mathrm{mDOF}$ elastic oscillators correspond to superstructures with $\mathrm{n}=\{3,6$ and 9$\}$ floors and shear displacement profile. The results are presented comparatively between the CAV and CRV impact assumption. The dynamic response of the rocking base is similar in both models. Despite the different values of the coefficient of restitution between the CAV and CAR assumptions, the energy loss during impact is comparable in both models. In the former case energy is dissipated exclusively by the rocking base while in the latter case energy is dissipated by the rocking base and the superstructure. Regarding the response of the superstructure the CAV assumption results in slightly larger elastic deformations.

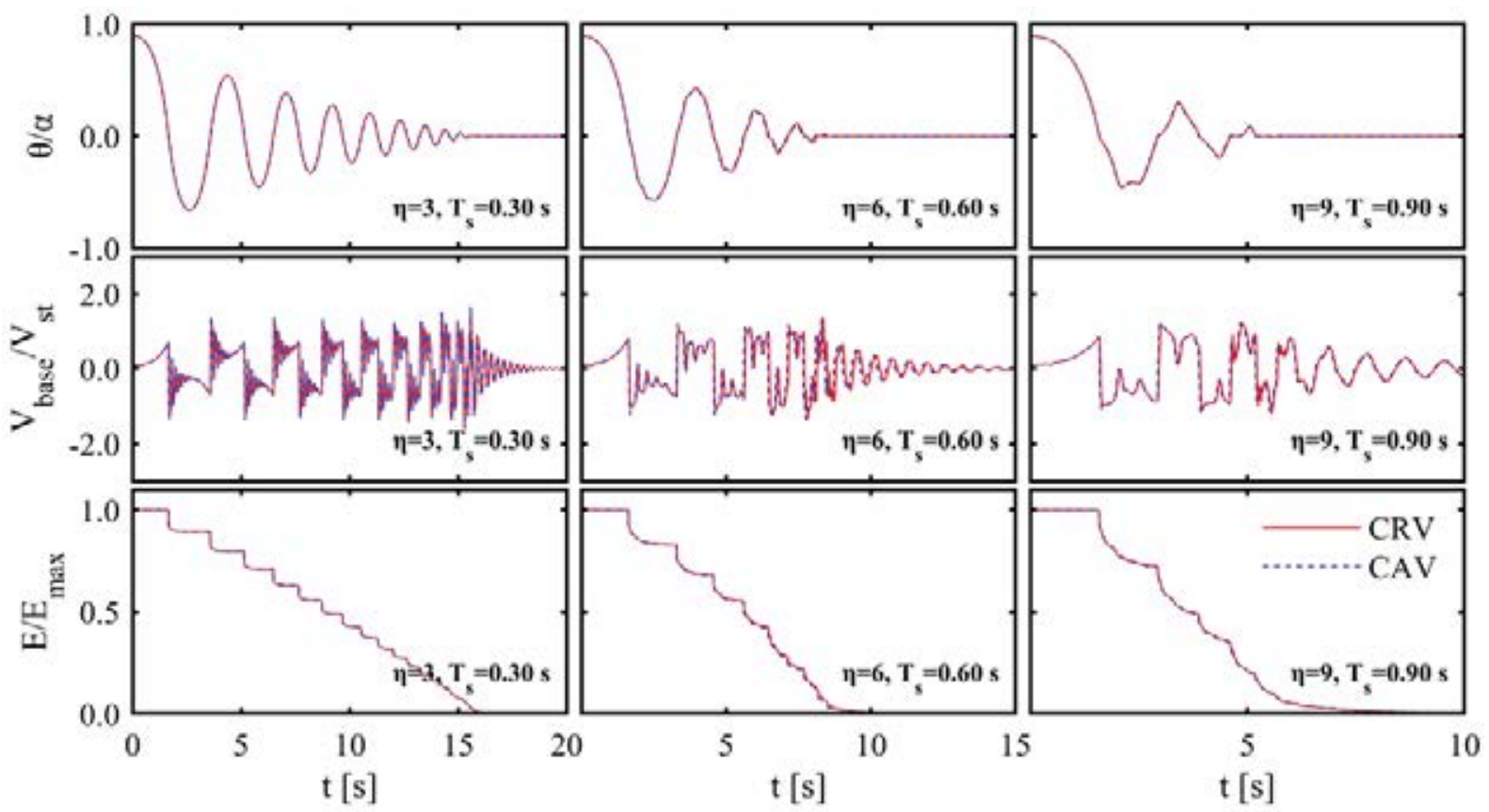

Figure 4: Response time histories under free rocking oscillations of the rocking base.

The maximum rocking response $\left(\theta_{\max } / \alpha\right)$ for each of the examined structures considering CRV and CAV assumption, under the set of the synthetic pulse-like ground motions, are presented in Figure 5. It can be observed that the majority of the data follows a trend. However, there are many cases where RPSs considering CRV assumption overturns, while assuming 
CAV assumption survives and vice versa. That fact is more intense in case of the 3 -storey superstructure. As the flexibility of the superstructure increases, the dispersion between the responses seems to be significantly decreased. However, the displacement profile of the superstructure seems not to affect the developed rocking rotations.
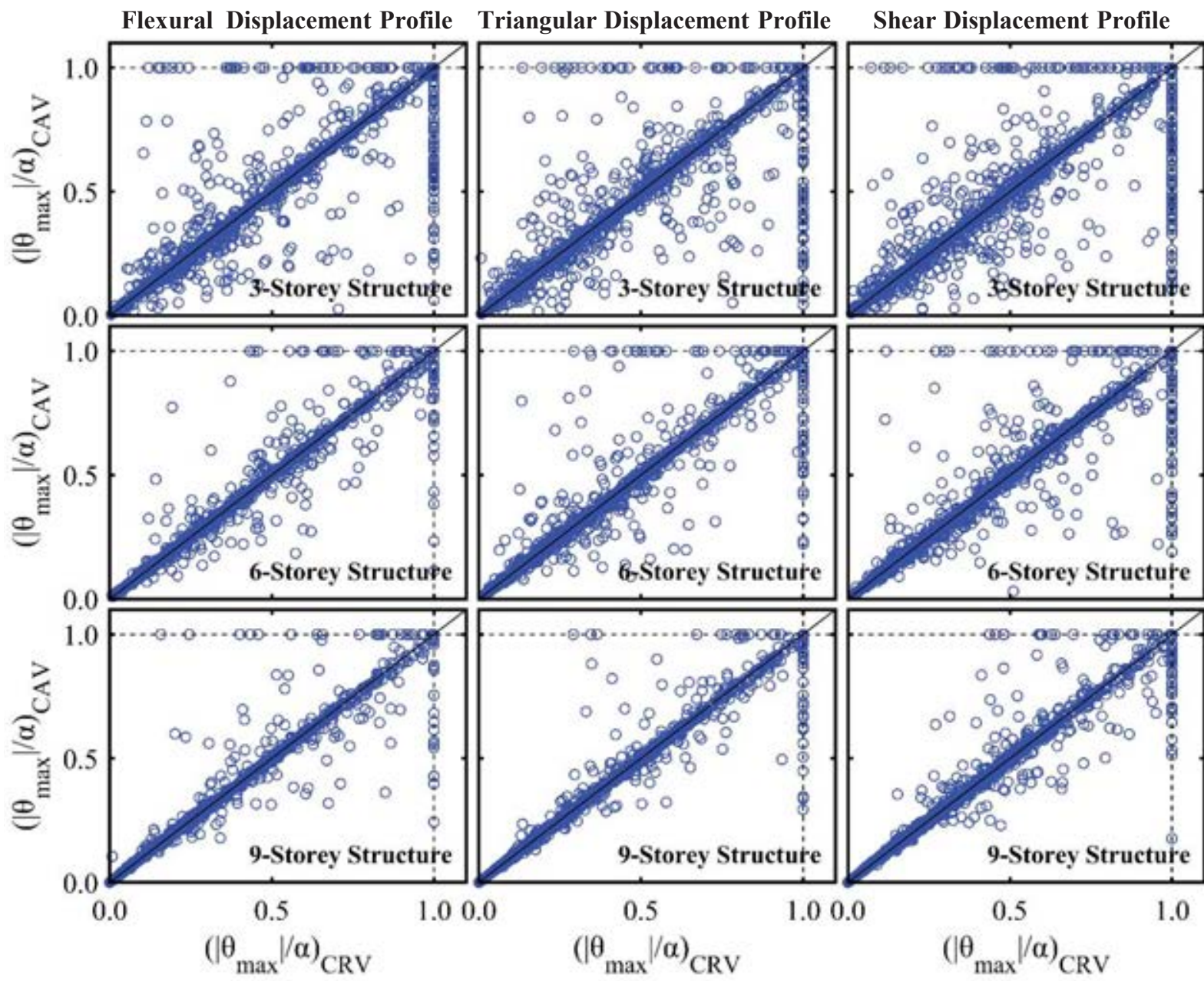

Figure 5: Comparison of the maximum rocking rotation calculated by the CRV and CAV assumption under the pulse like synthetic ground motions.

In order to examine the effect of the adopted assumption regarding the velocity of the superstructure during impact on the elastic seismic demands of mdof oscillators, the maximum shears developed on the multi-storey superstructures are presented in Figure 6. The seismic demands normalized to the horizontal base shear $\left(\mathrm{V}_{\mathrm{st}}\right)$, required to activate the rocking base under static conditions [22], as calculated using both impact assumptions are presented comparatively. The results obtained by ground motions that cause overturning of the rocking base are omitted. As emerged by the results of the tilt angles, the responses of the stiffer superstructure present higher dispersion. Moreover, the displacement profile of the superstructures seems to affect the estimated maximum shear. Specifically, the increase of the effective mass of the superstructure's first mode (from flexural to shear displacement profile) results in higher correlation between the maximum responses obtained by the two energy dissipation models. 


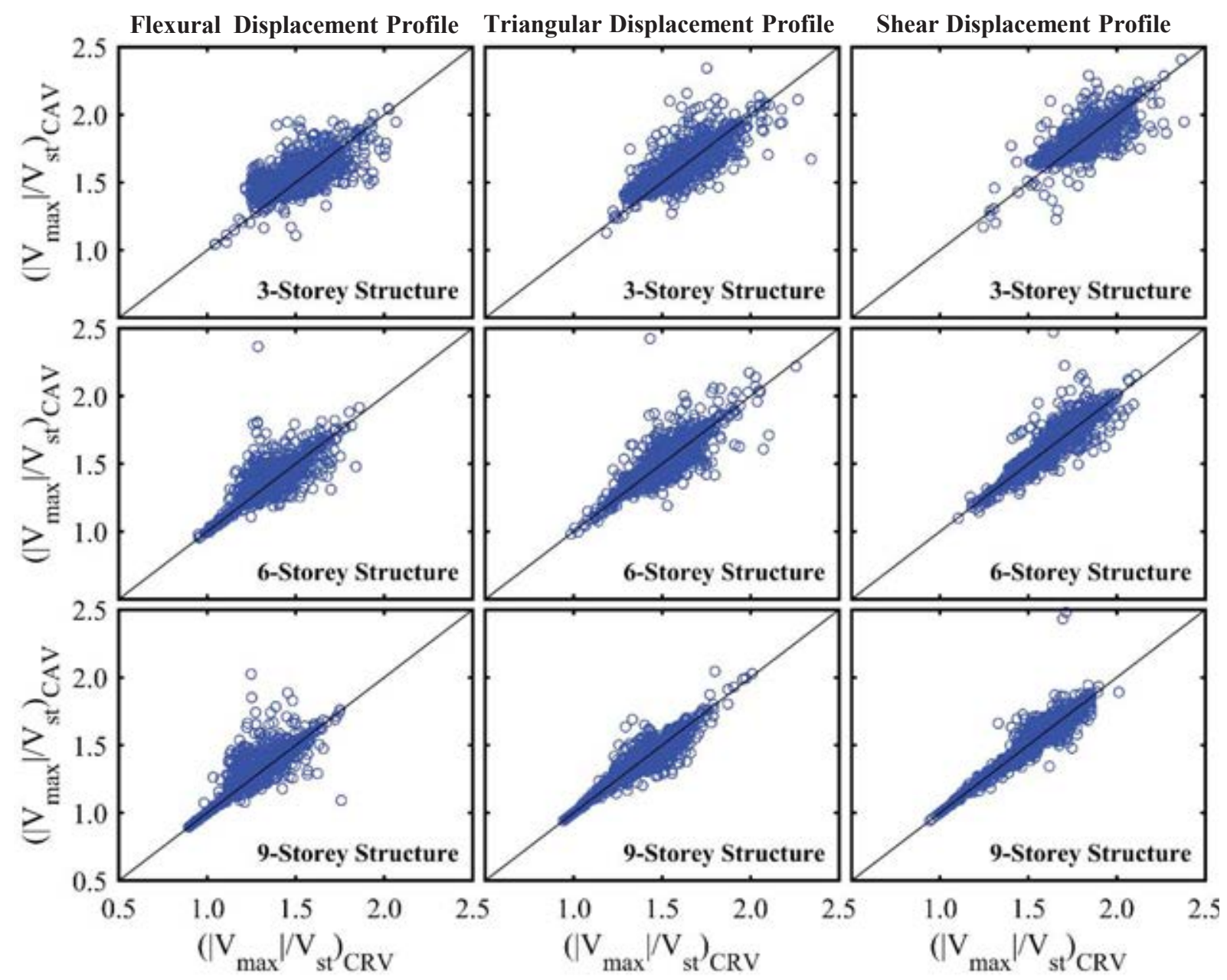

Figure 6: Comparison of the maximum normalized shear calculated by the CRV and CAV assumption under the pulse like synthetic ground motions.

In addition to the seismic demands in terms of maximum shear forces, their distribution throughout the superstructure is also of particular interest. Figure 7 presents the storey shears $\left(\mathrm{V}_{\mathrm{i}}\right)$ of the nine podium structures. The solid and dashed lines correspond to the average and maximum values of the storey seismic demands, respectively. In the same figure, the seismic demands of the superstructures considering CRV and CAV assumptions are presented comparatively. The results obtained by ground motions that cause overturning of the rocking base are omitted. The differences of the maximum values of the storey shears between the two impact assumptions seems to be important. However, regarding the mean values slight differences are depicted. In general, the CAV assumption results in increase of the shear in the lower floors. In upper floors the shears seems to be identical. The distribution pattern of the mean seismic demands presented by podium structures, regardless the impact assumption, indicates the excitation of higher modes of the superstructure during impact [23]. 


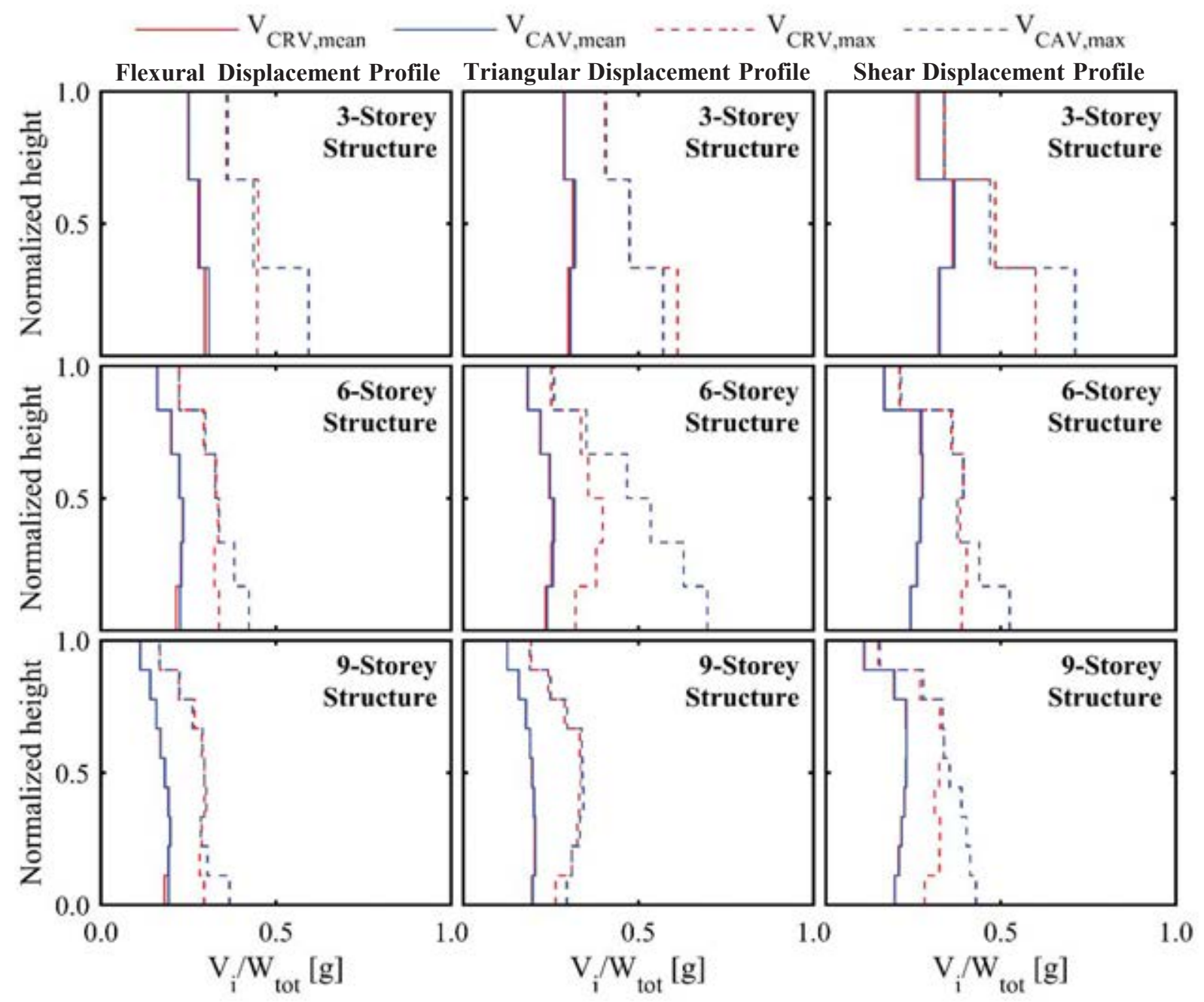

Figure 7: Average and maximum storey shear profiles (Vi).

In order to statistically assess the effect of the impact assumption on the dynamic response of the RPSs, following Bachmann et al. [45], empirical cumulative distribution functions (ECDFs) are constructed. In Figures 8 and 9 the ECDFs of the maximum rocking rotations of the base, as well as the maximum elastic seismic demands are presented, respectively. In each figure the ECDFs considering both CRV and CAV impact assumption is depicted. Moreover, the $95 \%$ confidence interval is reported for the ECDF calculated by the response results assuming CRV assumption. These plots illustrate the probability that the maximum response is smaller than a specific value of the response, in terms of tilt angle of the base $\left(\left|\theta_{\max }\right| / \alpha\right)$ or maximum shear of the superstructure $\left(\left|\mathrm{V}_{\max }\right| / \mathrm{V}_{\mathrm{st}}\right)$.

The ECDFs of the response of the rocking base considering CRV and CAV assumption are almost identical (Figure 8). Thus, statistically the two different assumptions regarding the velocity of the superstructure during impact do not affect the rocking response of RPSs. The effect of the superstructure's flexibility and lateral displacement profile on the response of the base can be observed throughout Figure 8. It has to be mentioned that the ECDFs of the 9storey superstructure indicate the lack of rocking initiation under a large amount of ground motion excitations $(>15 \%)$. 


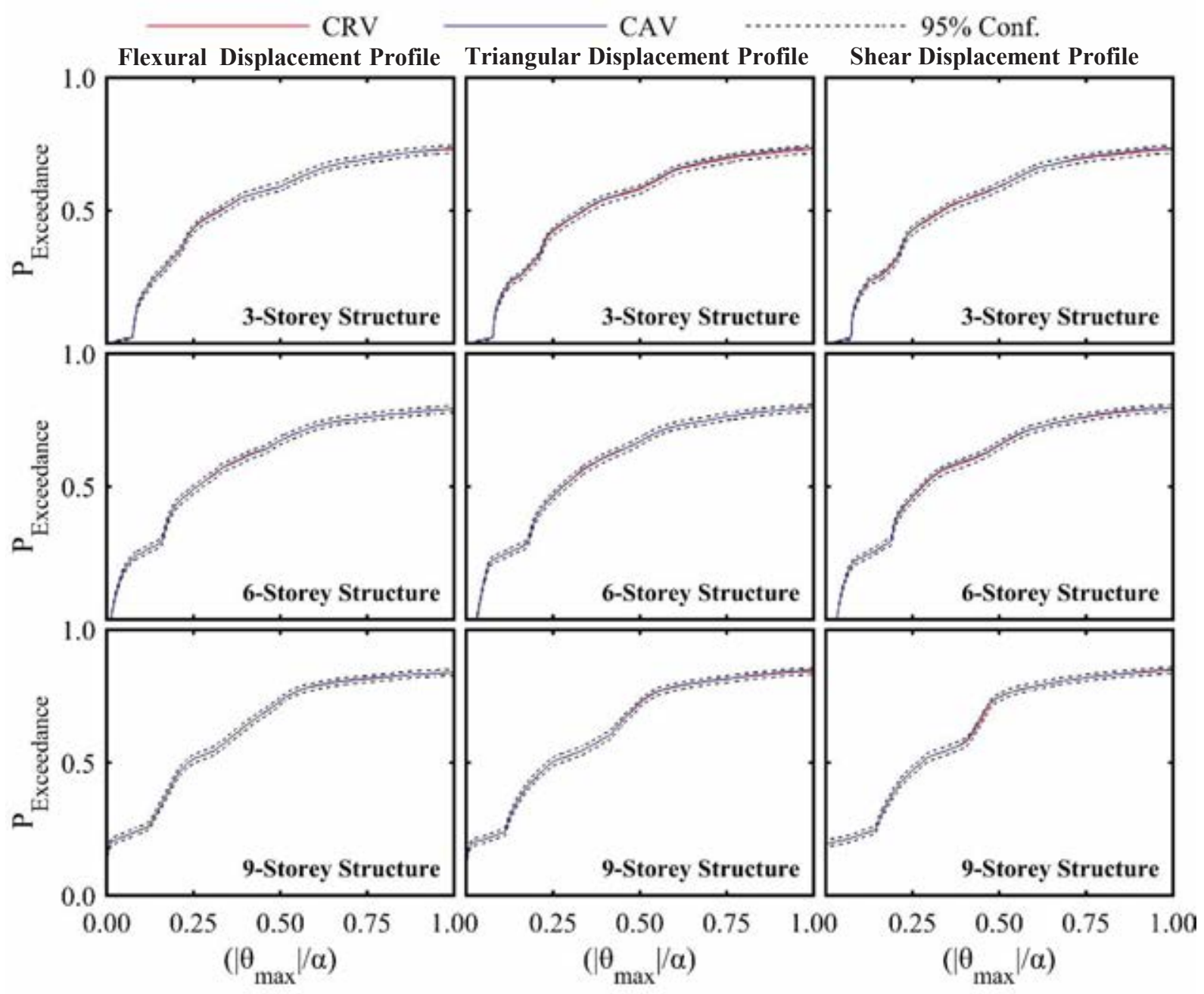

Figure 8: Cumulative distribution functions of the normalized maximum tilt angle $\theta_{\max } / \alpha$ for the synthetic pulse like ground motions.

In Figure 9 the ECDFs of the maximum superstructure's shear forces are presented. Unlike the response of the rocking base, the ECDFs of the seismic elastic demands considering the two impact assumptions present considerable differences. The variance of the responses is more intense in the 3-storey superstructure. As the flexibility of the superstructure increases the differences are diminished. The differences between the two impact models also tend to decrease as the effective mass the of the superstructure's first vibration mode increases. The ECDF by the CAV assumption is inside the confidence interval of the CRV assumption ECDF only in case of the 9-storey superstructure. In general, it is evident that CAV assumption results in increased elastic seismic demands. That fact is more intense in case of stiff superstructures. 


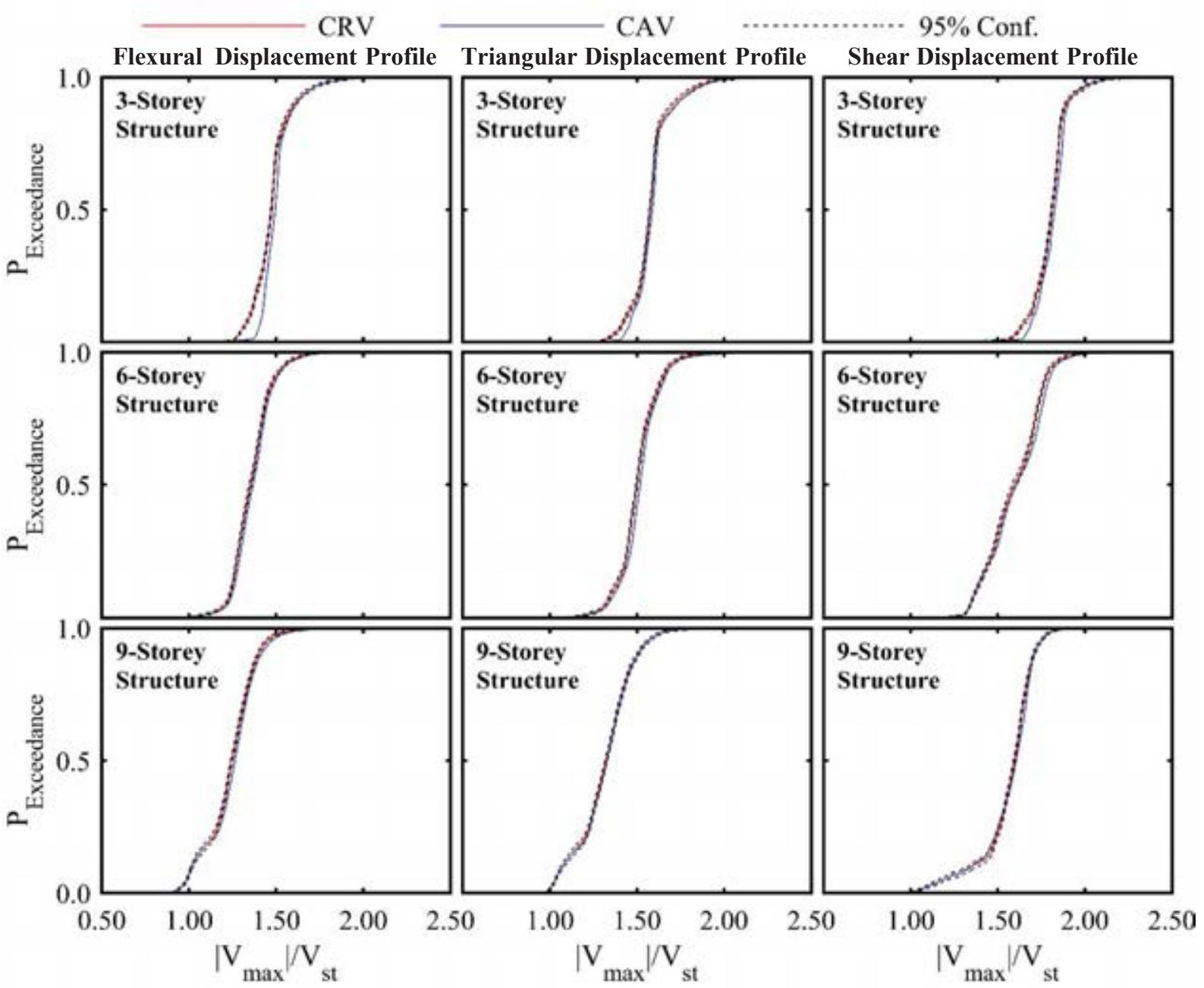

Figure 9: Cumulative distribution functions of the normalized base shear $V_{\max } / \mathrm{V}_{\text {st }}$ for the pulse like synthetic ground motions.

\section{CONCLUSION}

In the present study, the effect of the adopted energy dissipation modeling during impact on the response of multi-storey rocking podium systems are examined. Thus, two different assumptions regarding the velocity of the superstructure during impact is examined. Specifically, the assumptions of constant relative horizontal velocity and constant absolute horizontal velocity of the superstructure with respect to the cap beam of the rocking frame before and after the impact were considered.

The response time histories indicate that the assumptions regarding the impact model may result in diverging estimates of the tilt angle, especially in case of stiff superstructures. However, the response of the rocking base in terms of empirical cumulative density functions is not affected by the assumptions regarding the velocity of the superstructure during impact.

The effect of the impact assumption on the elastic seismic demands depends on the stiffness and the lateral displacements profile of the fundamental vibration mode of the superstructure. As the flexibility and the effective mass of the first mode of the superstructure increases, the effect of the two impact assumptions on the superstructure's response tend to be less notable. Examining especially stiff superstructures the CAV assumption results in higher elastic demands. 


\section{ACKNOWLEDGEMENTS}

This research is co-financed by Greece and the European Union (European Social FundESF) through the Operational Programme «Human Resources Development, Education and Lifelong Learning» in the context of the project "Reinforcement of Postdoctoral Researchers 2nd Cycle" (MIS-5033021), implemented by the State Scholarships Foundation (IKY).

\section{REFERENCES}

[1] G.W. Housner, The behavior of inverted pendulum structures during earthquakes. Bulletin of the Seismological Society of America, 53(2), 403-417, 1963.

[2] S. Acikgoz, M.J. DeJong, The rocking response of large flexible structures to earthquakes. Bulletin of Earthquake Engineering, 12(2), 875-908, 2014.

[3] S. Acikgoz, M.J. DeJong, Analytical modelling of multi - mass flexible rocking structures. Earthquake Engineering and Structural Dynamics, 45(13), 2103-2122, 2016.

[4] E. Avgenakis, I.N. Psycharis, Modeling of inelastic rocking bodies under cyclic loading. Journal of Engineering Mechanics, 146(4), 04020020, 2020.

[5] S. Diamantopoulos, M. Fragiadakis, Seismic response assessment of rocking systems using single degree-of-freedom oscillators. Earthquake Engineering and Structural Dynamics, 48(7), 689-708, 2019.

[6] M.F. Vassiliou, R. Truniger, B. Stojadinović, An analytical model of a deformable cantilever structure rocking on a rigid surface: development and verification. Earthquake Engineering and Structural Dynamics, 44(15), 2775-2794, 2015.

[7] I.N. Psycharis, Dynamics of flexible systems with partial lift-off. Earthquake Engineering and Structural Dynamics, 11(4), 501-521, 1983.

[8] C.S. Yim, A.K. Chopra, Simplified earthquake analysis of multistorey structures with foundation uplift. Journal of Structural Engineering, 111(12), 2708-2731, 1985.

[9] F. Gelagoti, R. Kourkoulis, I. Anastasopoulos, G. Gazetas, Rocking-isolated frame structures: margins of safety against toppling collapse and simplified design approach. Soil Dynamics and Earthquake Engineering, 32(1), 87-102, 2012.

[10] A. Palermo, S. Pampanin, D. Marriott, Design, modeling, and experimental response of seismic resistant bridge piers with post tensioned dissipating connections. Journal of Structural Engineering, 133(11), 1648-1661, 2007.

[11] J.A. Schaefer, B. Kennedy, M.O. Eberhard, J.F. Stanton, Unbonded pretensioned bridge columns with rocking detail. Technical Report PEER 2014/08, University of Washington, USA, 2014.

[12] A. Agalianos, A. Psychari, M.F. Vassiliou, B. Stojadinovic, I. Anastasopoulos, Comparative assessment of two rocking isolation techniques for a motorway overpass bridge. Frontiers in Built Environment, 3, 47, 2017.

[13] N. Makris, M.F. Vassiliou, Planar rocking response and stability analysis of an array of free-standing columns capped with a freely supported rigid beam. Earthquake Engineering and Structural Dynamics, 42(3), 431-449, 2013. 
[14] N. Makris, M.F. Vassiliou, Are some top-heavy structures more stable?. Journal of Structural Engineering, 140(5), 06014001, 2014.

[15] E.G. Dimitrakopoulos, A.I. Giouvanidis, Seismic response analysis of the planar rocking frame. Journal of Engineering Mechanics, 141(7), 04015003, 2015.

[16] A. Dar, D. Konstantinidis, W. El-Dakhakhni, Seismic response of rocking frames with top support eccentricity. Earthquake Engineering and Structural Dynamics, 47(12), 2496-2518, 2018.

[17] I.M. Thomaidis, A.J. Kappos, A. Camara, Dynamics and seismic performance of rocking bridges accounting for the abutment-backfill contribution. Earthquake Engineering and Structural Dynamics, 49(12), 1161-1179, 2020.

[18] A. Wada, Z. Qu, S. Motoyui, H. Sakata, Seismic retrofit of existing SRC frames using rocking walls and steel dampers. Frontiers of Architecture and Civil Engineering in China, 5(3), 259, 2011.

[19] N. Makris, M. Aghagholizadeh, The dynamics of an elastic structure coupled with a rocking wall. Earthquake Engineering and Structural Dynamics, 46(6), 945-962, 2017.

[20] M. Aghagholizadeh, N. Makris, Seismic response of a yielding structure coupled with a Rocking Wall. Journal of Structural Engineering, 144(2), 04017196, 2017.

[21] J.A. Bachmann, M.F. Vassiliou, B. Stojadinović, Dynamics of rocking podium structures. Earthquake Engineering and Structural Dynamics, 46(14), 2499-2517, 2017.

[22] K.E. Bantilas, I.E. Kavvadias, L.K. Vasiliadis, Analytical investigation of the seismic response of elastic oscillators placed on the top of rocking storey. Bulletin of Earthquake Engineering, 19, 1249-1270, 2021.

[23] K.E. Bantilas, I.E. Kavvadias, L.K. Vasiliadis, Seismic response of elastic multidegree of freedom oscillators placed on the top of rocking storey. Earthquake Engineering and Structural Dynamics, 50(5), 1315-1333, 2021.

[24] C.S. Yim, A.K. Chopra, J. Penzien, Rocking response of rigid blocks to earthquakes. Earthquake Engineering and Structural Dynamics, 8(6), 565-587, 1980.

[25] I.E. Kavvadias, L.K. Vasiliadis, A. Elenas, Seismic response parametric study of ancient rocking columns. International Journal of Architectural Heritage, 11(6), 791-804, 2017.

[26] I.E. Kavvadias, G.A. Papachatzakis, K.E. Bantilas, L.K. Vasiliadis, A. Elenas, Rocking spectrum intensity measures for seismic assessment of rocking rigid blocks. Soil Dynamics and Earthquake Engineering, 101, 116-124, 2017.

[27] E.G. Dimitrakopoulos, T.S. Paraskeva, Dimensionless fragility curves for rocking response to near-fault excitations. Earthquake Engineering and Structural Dynamics, 44(12), 2015-2033, 2015.

[28] I. Psycharis, M. Fragiadakis, I. Stefanou, Seismic reliability assessment of classical columns subjected to near-fault ground motions. Earthquake Engineering and Structural Dynamics, 42(14), 2061-2079, 2013.

[29] M. Fragiadakis, S. Diamantopoulos, Fragility and risk assessment of freestanding building contents. Earthquake Engineering and Structural Dynamics, 49(10), 1028-1048, 2020 . 
[30] A. Pappas, A. Sextos, F. Da Porto, C. Modena, Efficiency of alternative intensity measures for the seismic assessment of monolithic free-standing columns. Bulletin of Earthquake Engineering, 15(4), 1635-1659, 2017.

[31] F. Prieto, P.B. Lourenço, C.S. Oliveira, Impulsive Dirac-delta forces in the rocking motion. Earthquake Engineering and Structural Dynamics, 33(7), 839-857, 2004

[32] D. Kalliontzis, S. Sritharan, A. Schultz, Improved coefficient of restitution estimation for free rocking members. Journal of Structural Engineering, 142(12), 06016002, 2016.

[33] M.N. Chatzis, M.G. Espinosa, A.W. Smyth, Examining the energy loss in the inverted pendulum model for rocking bodies. Journal of Engineering Mechanics, 143(5), 04017013, 2017.

[34] A.K. Chopra, C.S. Yim, Simplified earthquake analysis of structures with foundation uplift. Journal of Structural Engineering, 111(4), 906-930, 1985.

[35] I.N. Psycharis, Effect of base uplift on dynamic response of SDOF structures. Journal of Structural Engineering, 117(3), 733-754, 1991.

[36] G. Oliveto, I. Calio, A. Greco, Large displacement behaviour of a structural model with foundation uplift under impulsive and earthquake excitations. Earthquake Engineering and Structural Dynamics, 32(3), 369-393, 2003.

[37] A.I. Giouvanidis, E.G. Dimitrakopoulos, Nonsmooth dynamic analysis of sticking impacts in rocking structures. Bulletin of Earthquake Engineering, 15(5), 2273-2304, 2017.

[38] P.G. Somerville, N.F. Smith, R.W. Graves, N.A. Abrahamson, Modification of empirical strong ground motion attenuation relations to include the amplitude and duration effects of rupture directivity. Seismological Research Letters, 68(1), 199-222, 1997.

[39] N. Makris, C.J. Black, Evaluation of peak ground velocity as a "good" intensity measure for near-source ground motions. Journal of Engineering Mechanics, 130(9), 1032-1044, 2004.

[40] G.P. Mavroeidis, A.S. Papageorgiou, A mathematical representation of near-fault ground motions. Bulletin of the seismological society of America, 93(3), 1099-1131, 2003 .

[41] R. Rupakhety, S.U. Sigurdsson, A.S. Papageorgiou, R. Sigbjörnsson, Quantification of ground-motion parameters and response spectra in the near-fault region. Bulletin of Earthquake Engineering, 9(4), 893-930, 2011.

[42] D.M. Boore, Simulation of ground motion using the stochastic method. Pure and Applied Geophysics, 160(3), 635-676, 2003.

[43] G.M. Atkinson, W. Silva, Stochastic modeling of California ground motions. Bulletin of the Seismological Society of America, 90(2), 255-274, 2000.

[44] G.E. Thermou, S.J. Pantazopoulou, A.S. Elnashai, Global interventions for seismic upgrading of substandard RC buildings. Journal of Structural Engineering, 138(3), 387401, 2012.

[45] J.A. Bachmann, M. Strand, M.F. Vassiliou, M. Broccardo, B. Stojadinović, Is rocking motion predictable?. Earthquake Engineering and Structural Dynamics, 47(2), 535-552, 2018. 